\title{
Effect on heart rate and blood pressure after mental stress in coronary artery disease patients and normal individuals
}

\author{
Esha Shrestha' ${ }^{1}$ Shreesh Shrestha ${ }^{2}$, Tapas Pramanik ${ }^{3}$, Smriti Singh $^{3}$
}

\section{Author(s) info:}

${ }^{1}$ Department of Physiology, National Medical College and Teaching

Hospital, Birgunj, Nepal

${ }^{2}$ Department of Internal Medicine,

Virginia Commonwealth University,

Virginia, USA

${ }^{3}$ Department of Physiology, Nepal Medical College and Teaching

Hospital, Kathmandu, Nepal

\section{Correspondence:}

Dr. Esha Shrestha, MBBS, $M D$

Department of Physiology, National Medical College and Teaching

Hospital, Birgunj, Nepal

Email:

dr.estha@gmail.com

DOI :

https://doi.org/10.3126/jpsn.v2i1.42588

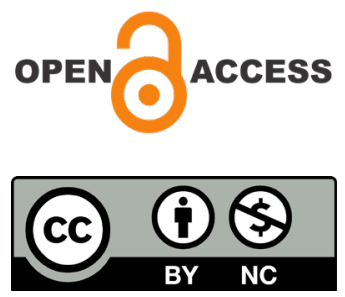

C JPSN

\begin{abstract}
Introduction: Cardiovascular diseases are the leading cause of death in almost every region of the world. One of the major risk factors for coronary artery disease is stress. The study was carried out to find the effect of mental stress on heart rate and blood pressure in coronary artery disease patients and in their age-matched normal counterparts.
\end{abstract}

Materials and methods: Blood pressure and heart rate were recorded before and immediately after standardized mental stress (mental calculation for a minute) after necessary instruction among the volunteers $(n=100,50$ coronary artery disease patients and 50 control, age 40-80 years) and then analyzed.

Results: The mean HR was $75.40 / \mathrm{min}$ and the mean SBP was 121.84 $\mathrm{mmHg}$ of patient before stress which increased to $80.26 / \mathrm{min}$ (HR) and $135.12 \mathrm{mmHg}$ (SBP) after stress. Similarly, the mean HR was $76.72 / \mathrm{min}$ and SBP was $116.24 \mathrm{mmHg}$ before stress which increased to $80.5 / \mathrm{min}$ (HR) and $121.56 \mathrm{mmHg}$ (SBP) after stress in normal individual. The result of the study showed mental stress induced rise in heart rate and blood pressure in both the groups. Nevertheless, mental stress induced increase in systolic blood pressure in patients exhibited higher than that of their aged-matched normal counterparts $(\mathrm{p}<0.05)$.

Conclusions: The incidence of coronary artery disease is increasing day by day in the modern society. The measurement of heart rate and blood pressure (casual and mental stress induced) may help the clinicians to predict/screen coronary artery disease, especially the silent ones, and can prevent sudden angina pain.

Keywords: Blood pressure; cardiovascular disease; heart rate; mental stress 


\section{INTRODUCTION}

Stress is the inflict on any subject when a person required the degree to which they feel overwhelmed or unable to cope as a result of pressures that are unmanageable.[1] People experiencing stress, depression, angina may experience certain physiologic effects on the body, such as increased cardiac reactivity like increased heart rate (HR) and blood pressure (BP), reduced blood flow to the heart, and heightened levels of cortisol. Over time, these physiologic effects can lead to calcium buildup in the arteries, metabolic disease, and heart disease.[2] When a person is exposed to stress for a long period of time, then there may be increased chance of atherosclerosis, inflammatory reactivity, endothelial dysfunction, and oxidative stress, which are the primary factors to the development of eventual cardiovascular diseases.[3]

Cardiovascular diseases (CVD) are the leading cause of death in almost every region of the world. [4-6] Chronic coronary syndrome is a failure of coronary circulation to supply adequate blood circulation to cardiac muscle and surrounding tissue - a phenomenon that may result in a myocardial infarction (MI).[7] The main risk factors for coronary artery disease (CAD) include dyslipidemia, diabetes, arterial hypertension, obesity, smoking, and a sedentary lifestyle, as well as stress, older age, male gender, and a family history of coronary heart disease (CHD).[8]

This mental stress triggers the sympatheticadrenal-medullary axis leading it to discharge catecholamine, which consequently elevates $\mathrm{BP}$ and HR with increased workload on heart. $[9,10]$ In this context, it is justified to see how much alteration may occur in HR and BP due to mental stress in patients with $\mathrm{CAD}$ and in normal individuals. Present study was undertaken to compare the alteration in mental stress induced HR and BP in patients with CAD and in normal individuals.

\section{MATERIALS AND METHODS}

A comparative descriptive study was conducted in Shahid Gangalal National Heart Center (SGNHC) over one year. Ethical approval was obtained from the institutional review committee of Nepal Medical College and permission letter was obtained from SGNHC. The study population comprised of 50 patients with myocardial infraction (27 males and 23 females) and 50 healthy individuals (25 males and 25 females) with age group 40-80 years. Informed written consent was obtained from all the participants. All patients had CAD, and none had undergone coronary artery bypass surgery. Those patients who had done bypass surgery were excluded. All normal healthy individuals having no CAD, chest symptom and not under any medication related to cardiac problem.

After recruitment, detail clinical history of all the particiapants was taken. An electrocardiogram (ECG) was done in all volunteers. Myocardial Infraction was confirmed by cardiac markers (CPKMB and troponin I) along with ECG and history.

For every volunteer casual blood pressure and heart rate were recorded before the experimental procedure. Blood pressure was measured by auscultatory method using mercury sphygmomanometer and stethoscope (Littman Cardiosonic) keeping the individual in sitting posture with a back rest after allowing him/her to take rest at least for 5 minutes. Heart rate was measured by cardiac auscultation in mitral area for 1 min immediately after taking BP measurement. The CAD patients were requested to perform mental arithmetic calculation for a minute with serial subtractions of 7 from 100 as quickly as possible. A metronome at the rate of 90 beats/min was kept, which acted as an additive stressor component. The subjects were repeatedly asked to increase the speed by urging comments such as 'Try to go a little faster!', 'Follow the sound of metronome!' etc. The number of correct responses was recorded, but wrong answers were immediately corrected by asking the subject to correct it. Throughout the test, the experimenter encouraged the subjects to perform at his/her maximum speed, but maintained an emotionally neutral attitude to prevent the subjects from a feeling of being harassed. Blood pressure and heart rate were recorded immediately after the calculation.

Same procedure was performed on the control group and heart rate and BP measured similarly.

All the data were collected and analyzed statistically by using students'-test to find out significant variation between two study groups. The statistical analysis (t-test) was performed by SPSS version 20 . 
Table 1: Hemodynamic parameters of CAD patients and normal individuals

\begin{tabular}{|l|c|c|c|c|c|c|}
\hline \multicolumn{1}{|c|}{ Parameter } & \multicolumn{3}{|c}{ Patient } & \multicolumn{3}{c|}{ Controls } \\
\cline { 2 - 8 } & At rest & $\begin{array}{c}\text { After mental } \\
\text { stress }\end{array}$ & P value & At rest & $\begin{array}{c}\text { After mental } \\
\text { stress }\end{array}$ & P value \\
\hline HR (beat/min) & $75.40 \pm 10.43$ & $80.26 \pm 10.94$ & $>0.05$ & $76.72 \pm 8.85$ & $80.56 \pm 9.46$ & $>0.05$ \\
\hline SBP $(\mathrm{mmHg})$ & $121.84 \pm 15.07$ & $135.12 \pm 13.4$ & $<0.05$ & $116.24 \pm 14.75$ & $121.56 \pm 15.4$ & $<0.005$ \\
\hline DBP $(\mathrm{mmHg})$ & $78.44 \pm 11.17$ & $82.40 \pm 10.84$ & $>0.05$ & $76.2 \pm 8.96$ & $78.88 \pm 8.85$ & $>0.05$ \\
\hline
\end{tabular}

\section{RESULTS}

The study was carried out among 50 myocardial infraction patients (27 male and 23 female), and 50 healthy individuals ( 25 male and 25 female) with age 40-80 yrs. ECG of all patients showed STelevation in different leads, CPKMB were found to have more than $35 \mathrm{UL}$ (mean $150 \mathrm{UL}$ ) and all blood samples were troponin-I positive. All patients were receiving $\beta$-blockers and none had undergone coronary artery bypass graft.

The resting heart rate of normal individuals is more than patients and the resting blood pressure of patients is more than the normal individuals. After mental stress the HR, SBP and DBP all increased in both patients and normal individuals. (Table. 1) The heart rate increased only slightly (insignificantly) in patients (6.53\% from the baseline) and in normal counterparts $(5.01 \%$ from the baseline), DBP increase is negligible both in patients $3.04 \%$ from baseline) and normal individuals (3.62\% from baseline) but rise in SBP was highly significantly in patients (11.36\% from baseline) than their normal counterparts (4.63\% from baseline).(Figure.1)

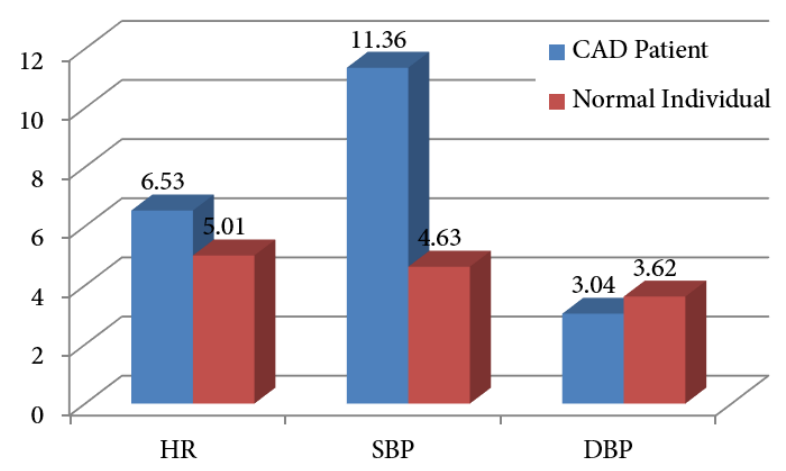

Figure 1. Mental stress induced rise (\%) in HR, SBP, and DBP among the CAD patients and normal individuals

\section{DISCUSSION}

In present study, we included the patients who were diagnosed as coronary artery disease and control group who never had cardiac disease. Here we compared the rise in HR and BP among patient and control group after mental stress. We administered mental arithmetic as a stressor, as previous studies established it as a less potent stimulus than public speaking task in eliciting myocardial ischemia in CAD patients.[11,12] Besides that, the patients were subjected to mental arithmetic (stressor) in hospital setting, so that if by chance anginal pain would occur as a result of myocardial ischemia the situation could be managed by using life supporting drugs and the specialist's care. Normal volunteers were also subjected to the same stressor.

In present study, casual/baseline $\mathrm{HR}$ in $\mathrm{CAD}$ patients was found to be lesser than that of their normal counterparts. It may be due to the effect of $\beta$-blocker (metoprolol) which was administered in all CAD patients who took part in our study. Casual/baseline BP in CAD patients was higher than the same in their normal counterparts as those patients were already in stress leading to raised plasma catecholamine level. Schoder et al also found higher baseline titer of serum epinephrine and Norepinephrine (Epi: 36pg/ml; NE: 289pg/ $\mathrm{ml}$ ) in CAD than in normal counterparts (Epi: 29pg/ml;NE: $258 \mathrm{pg} / \mathrm{ml}$ ).[1] Increased titer of catecholamines might be the cause of raised causal/ baseline BP.

Mental Stress through mental arithmetic task increased HR by about 6\% in both normal volunteers and CAD patients in the present study. But the study done by Emilie Pérusse-Lachance et al.,[14] found that mental stress in the form of 45min reading-writing session, elevated HR by $10 \%$. This finding was in line with Martin et al.,[15] who reported an increase in HR by $20 \%(+6.7 \mathrm{bpm})$, and Durocher et al., [16] also noted a similar 
increase of HR approximately $20 \%$ during a single arithmetic task of 5-min duration. Mental stress also increases both SBP and DBP in CAD patients and normal individuals which was due to release of catecholamine in response to stress through sympathetic stimulation. The catecholamine (epinephrine) resulted increased in rate and force of contraction of heart leading to increased heart rate and SBP.[17] Another possibility is an increased or decreased muscle sympathetic nerve stimulation, which exemplifies the actions of the sympathetic nervous system[18] as a result of mental activity.

It was unique in that generally DBP decreases or remains same in physical exercise but in the case of mental stress DBP increases slightly both in normal and CAD patients indicating raised SVR in both the cases.[19]

Mental stress induced increased in $\mathrm{HR}$ and $\mathrm{BP}$ was not severe in normal individuals than in CAD patients. Stress caused increased in catecholamine that increased the HR mediated by $\beta 1$ receptor. Mental stress cause moderate increased in cardiac work. When blood norepinephrine titer increases slowly in human, BP (both SBP and DBP) rises. Hypertension stimulates carotid and aortic baroreceptor producing reflex bradycardia that overrides the direct cardio-accelerating effect of norepinephrine.[20] So, HR and BP increased only slightly.

A rapid upregulation of beta adrenoceptors occurs during myocardial ischemia. This upregulation occurs in spite of a massive release of norepinephrine from cardiac adrenergic nerves during ischemia. Both norepinephrine release and upregulation of cardiac beta adrenoceptors lead to an adrenergic overstimulation of ischemic myocardium.[21] $\beta$-blocker significantly reduced peak mental stress heart rate; but mental stress triggered blood pressure elevation were not affected.[22] So heart rate increased only slightly in CAD patients, but rise in SBP was higher which may be due to increased SBP reactivity to mental stress. [23]

The study by Merz et al revealed heightened cardiovascular reactivity, measured by magnitude in blood pressure elevation from baseline, among the patients, who displayed the most severe mentalstress- triggered ischemia.[22] Present study also recorded higher mental- stress- triggered elevation of SBP in CAD patients $(11.36 \%$ increase from baseline) compared to the same in their normal age-matched counterparts $(4.63 \%$ increase from baseline).

Norepinephrine produces vasoconstriction in most of the organs via $\alpha_{1}$ receptor.[20] NE titer was found to be higher in $\mathrm{CAD}$ patients than in normal counterparts during mental stress.[13] So, mental stress induced DBP was higher in CAD patients than that in normal counterpart.

\section{CONCLUSION}

The measurement of HR and BP (casual and mental stress induced) may help the clinicians to predict/ screen CAD, especially the silent ones, and can prevent sudden anginal pain in them. The result of the present study indicated that if mental stress induced rise in SBP is more than $\sim 10 \%$ than that of casual SBP; it is recommended that the individual should be advised to go for ECG and other tests for further evaluation of cardiac function to do the needful. This may also be useful in prediction/early detection of CAD in remote areas where advanced diagnostic facilities (like ECG, cardiac enzyme measurement) is not available unfortunately.

The patients were treated with angiotensin converting enzyme inhibitor, nitrate and other angina drugs which had been shown to improve the coronary endothelial dysfunction. So, the true degree of effect of stress on BP and HR may be underestimated. The sample size is also less due to limited time and feasibility so it is too early to announce the cut of percentage of blood pressure.

\section{ACKNOWLEDGEMENT}

We would like to thank Sahid Gangalal National Heart Institute for allowing us to collect data. We would also like to thank all the patients for their cooperation.

\section{CONFLICT OF INTEREST}

None.

\section{REFERENCES}

1. Kim HG, Cheon EJ, Bai DS, Lee YH, Koo BH. Stress and Heart Rate Variability: A Meta-Analysis and Review of the Literature. Psychiatry Investig 2018;15(3):235-45. DOI: 10.30773/pi.2017.08.17.

2. Shephard B. A war of nerves: soldiers and psychiatrists in 
the twentieth century. The American Historical Review 2001;106(5):1763-64. DOI:10.1086/ahr/106.5.1763.

3. Pandey KR, Khadka R, Panday DR, Agrawal K, Paudel $B H$. Influence of acute mental stress on blood pressure, heart rate and heart rate variability in male medical students: An experimental study from tertiary care hospital, Nepal. JBS 2020;7(1):11-17. DOI: https://doi. org/10.3126/jbs.v7i1.29848.

4. Shepard D, Vander Zanden A, Moran A, Naghavi M, Murray C, Roth G. Ischemic heart disease worldwide 1990 to 2013: estimates from the global burden of disease study 2013. Circ Cardiovasc Qual Outcomes 2015;8(4):455456. DOI: 10.1161/CIRCOUTCOMES.115.002007.

5. Benziger CP., Roth GA., Moran AE. The global burden of disease study and the preventable burden of NCD. Glob Heart 2016;11(4):393-397. DOI: 10.1016/j. gheart.2016.10.024.

6. Foley JR, Plein S, Greenwood JP. Assessment of stable coronary artery disease by cardiovascular magnetic resonance imaging: current and emerging techniques. World J Cardiol 2017;9(2):92-108. DOI: 10.4330/wjc. v9.i2.92.

7. De Hert M, Correll CU, Bobes J,Bakmas MC, Cohen D, asai I et al. Physical illness in patients with severe mental disorders. I. Prevalence, impact of medications and disparities in health care. World Psychiatry 2011;10(1):5277. DOI: 10.1002/j.2051-5545.2011.tb00014.x.

8. Nasitowska-Barud A, Zapolski T, Barud M, Wysokinski A. Overt and covert anxiety as a toxic factor in ischemic heart disease in women: the link between psychological factors and heart disease. Med Sci Monit 2017;23:751758. DOI: $10.12659 / \mathrm{msm} .902544$.

9. DJ Crews, DM Landers. A meta-analytic review of aerobic fitness and reactivity to psychosocial stressors. Medicine \& Science in Sports \& Exercise. 1987;19(5, Suppl): 114120. DOI: https://doi.org/10.1249/00005768-19871000100004.

10. Huang CJ, Webb HE, Zourdos MC, Acevedo EO. Cardiovascular reactivity, stress, and physical activity. Front Physiol 2013;4:314 . https://doi.org/10.3389/ fphys.2013.00314.

11. LaVeau PJ, Rozanski A, Krantz DS, Cornell CE, Cattanach $L$, Zaret BL et al. Transient left ventricular dysfunction during provocative mental stress in patients with coronary artery disease. Am Heart J 1989;118:1-8. DOI: https://doi. org/10.1161/01.CIR.94.10.2402.

12. Ironson G, Taylor CB, Boltwood M, Bartzokis T, Dennis $C$, Chesney $M$ et al. Effects of anger on left ventricular ejection fraction in coronary artery disease. Am J Cardiol
1992;70:281-5. DOI: 10.1016/0002-9149(92)90605-x.

13. Schoder H, Silverman DH, Campisi R, Karpman H, Phelps ME, Schelbert HR et al. Effect of mental stress on myocardial blood flow and vasomotion in patients with coronary artery disease. J Nuclear Med 2000;41:11-6. DOI:https://doi.org/10.1161/JAHA.113.000321.

14. Pérusse-Lachance E, Tremblay A, Chaput JP, Poirier P, Teasdale N, Drapeau V. Mental Work Stimulates Cardiovascular Responses through a Reduction in Cardiac Parasympathetic Modulation in Men and Women, Bioenergetics 2012;2(1):1-6. DOI:10.1249/01. MSS.0000402077.918 46.d8.

15. Martin EA, Tan SL, MacBride LR, Lavi S, Lerman $L O$, Lerman A. Sex differences in vascular and endothelial responses to acute mental stress, Clin. Auton. Res 2008;18(6):339-45. DOI: 10.1007/s10286-008-04975.

16. Durocher JJ, Klein JC, Carter JR. Attenuation of sympathetic baroreflex sensitivity during the onset of acute mental stress in humans. Am J Physiol Hear. Circ Physiol 2011;300(5):H1788-93. DOI: https://doi. org/10.1152/ajpheart.00942.2010.

17. Berne RM, Levy MN, Koeppen BM, Stanton BA. Physiology, 5th ed. USA: Elsevier Mosby 2004: 883-919.

18. Carter JR, Durocher JJ, Kern RP. Neural and cardiovascular responses to emotional stress in humans. Am. J. Physiol. Regul. Integr. Comp. Physiol 2008;295(6):R1898-903. DOI: https://doi.org/10.1152/ ajpregu.90646.200.

19. Goldberg AD, Becker LC, Bonsall R, Cohen JD, Ketterer $M W$, Kaufman $P G$ et al. Ischemic, hemodynamic, and neuro-hormonal responses to mental and exercise stress: experience from the Psycho-physiological Investigations of Myocardial Ischemia study (PIMI). Circulation 1996;94:2402-9. DOI: https://doi.org/10.1161/01. CIR.94.10.2402.

20. Barrett KE, Baeman SM, Boitano S, Brooks HL. Ganong's review of medical physiology, 24th ed. New York: The McGraw-Hill 2012: 357.

21. Haeusler G. Pharmacology of beta-blockers: classical aspects and recent developments. J Cardiovasc Pharmacol 1990; 16 Suppl: 1-9.

22. Bairey Merz CN, Krantz DS, Rozanski A. Mental stress and myocardial ischemia. Behav Aspect Heart Dis 1993;20:152-7.

23. Krantz DS, Helmers KF, Bairey CN, Nebel LE, Hedges SM, Rozanski A. Cardiovascular reactivity and mental stressinduced myocardial ischemia in patients with coronary artery disease. Psychosom Med 1991;53:1-12. 